\title{
Desain Media Komunikasi Visual Berbentuk Tabloid Sebagai Sarana Promosi SMK Mandiri 2
}

\section{The Design of Visual Communication Media in the Form of Tabloid as a Means of Promotion of SMK Mandiri 2}

\author{
Giandari Maulani ${ }^{1}$, Siti Nur Janah ${ }^{2}$, Yuri Alam Mahbubi ${ }^{3}$ \\ 1,2,3 STMIK Raharja Tangerang; Jl.Jendral Sudirman No.40 Modern,Cikokol,Tangerang, \\ (021) 5529692, (021) 5529742 \\ 1,2,3 Jurusan Sistem Informasi STMIK Raharja Tangerang \\ ${ }^{1}$ giandari@ raharja.info, ${ }^{2}$ siti.nurjanah@ raharja.info, ${ }^{3}$ yuri.alam@ raharja.info
}

\begin{abstract}
Abstrak
SMK Mandiri 2 merupakan salah satu lembaga pendidikan yang membutuhkan promosi dalam memperkenalkan sekolahnya kepada masyarakat. Pembuatan desain media komunikasi visual ini akan dijadikan sebagai media informasi dan promosi SMK Mandiri 2. Untuk metodologi yang digunakan pada penelitian ini, diantaranya metode analisis permasalahan, metode pengumpulan data, metode analisis perancangan dan metode konsep desain. Permasalahan yang ada saat ini SMK Mandiri 2 dalam menunjang kegiatan promosinya belum menggunakan media komunikasi visual dan berdasarkan analisis permasalahan tersebut maka dibuatlah desain media komunikasi visual dalam bentuk Tabloid yang bertujuan agar promosi dengan tabloid dapat menjangkau masyarakat lebih luas lagi, terutama menerapkan strategi pemasaran yang menarik minat calon siswa-siswi baru. Dalam menunjang kegiatan promosinya pihak sekolah membutuhkan sebuah media komunikasi visual yang dinilai efektif maka melalui desain media komunikasi visual berbentuk tabloid ini diharapkan dapat memberikan banyak informasi, diterima berbagai kalangan, serta dapat meningkatkan nama baik sekolah SMK Mandiri 2 agar semakin dikenal oleh masyarakat luas.
\end{abstract}

Kata kunci-Desain media komunikasi visual, Tabloid, Promosi.

\begin{abstract}
SMK Mandiri 2 is one of the institutions who need promotion in introducing the school to the community. The creation of this visual medium of communication design will serve as a medium of information and promotion of SMK Mandiri 2. For the methodology used in this research, including methods of analysis, problems, methods of data collection, methods of analysis and design method of the design concept. Existing problems of current SMK Mandiri 2 in support of promotion is not yet using visual communication and media based on analysis of these problems then the Congressional design visual communication media in the form of a Tabloid that aims so promotion with the tabloids can reach the public more broadly, especially to apply marketing strategies that attract new prospective students. In its promotional activities to support the school requires a media of visual communication which was assessed as effective then through visual communication media design tabloid is expected to provide a lot of information, received various backgrounds, and can increase the good name of the school SMK Mandiri 2 so increasingly known by the public at large.
\end{abstract}

Keywords - The design of visual communication media, Tabloids, Promotions. 


\section{PENDAHULUAN}

Media komunikasi visual merupakan suatu bentuk komunikasi dengan menggunakan desain grafis yang didalamnya terdapat unsur tipografi, fotografi dan ilustrasi. Media komunikasi visual adalah sarana untuk penyampaian pesan atau informasi kepada public yang dirangkai dengan penggunaan media penggambaran yang hanya dapat terbaca oleh indera penglihatan[1]. Perkembangan media informasi dan promosi yang semakin modern mempengaruhi sistem promosi sebuah lembaga pendidikan. Modern yang dimaksud dalam hal ini adalah hal-hal yang berkaitan dengan desain yang dibuat menarik dan menggunakan data yang up to date. Media promosi sendiri sangat berpengaruh pada sejumlah lembaga pendidikan,dalam hal ini sekolah-sekolah swasta. Berbagai cara dilakukan oleh sekolah untuk terus melebarkan sayapnya agar dikenal oleh masyarakat luas. Penggunaan media komunikasi visual dalam dunia pendidikan menjadi sangat penting, karena masyarakat membutuhkan sebuah informasi sekolah yang memiliki reeputasi baik untuk menyekolahkan putra-putri mereka nantinya. Sekolah Menengah Kejuruan (SMK) merupakan salah satu pilihan untuk para siswa dalam menentukan kemana arah yang akan mereka tempuh setelah lulus dan bekerja dimana mereka nantinya. Setiap Sekolah harus memiliki media informasi dan promosi yang menarik sehingga mampu dikenal masyarakat luas secara positif dan mampu menarik minat masyarakat untuk mendaftarkan putra-putrinya. Berbagai upaya dilakukan oleh SMK MANDIRI 2 untuk mencapai hal tersebut dan kegiatan yang paling berperan penting saat ini adalah dengan promosi. Promosi dapat dilakukan dengan penyebaran informasi melaluli media seperti brosur, leaflet, spanduk, baliho, kartu nama, booklet, seragam dan lain sebagainya. Akan tetapi dari semua contoh diatas, bentuk dari media yang paling tepat untuk mempromosikan sekolah yaitu dengan media Tabloid, karena Tabloid merupakan media komunikasi visual yang dinilai efektif dalam menyampaikan informasi dan promosi serta dapat mengenalkan kualitas dan keunggulan sekolah SMK Mandiri 2 dengan disertai gambar yang menarik. Berdasarkan hasil wawancara dan analisa kebutuhan Stakeholder SMK Mandiri 2, saat ini pihak sekolah masih menggunakan media promosi yang berupa banner dan brosur saja dalam menunjang kegiatan promosi sekolah pada setiap tahunnya. Melihat perkembangan akan media informasi dan promosi yang semakin berkembang pesat dengan berbagai ragam jenisnya, maka pihak sekolah membutuhkan sebuah desain media promosi yang tepat dan efektif yang dapat memberikan konstribusi positif dalam penyampaian suatu informasi mengenai kegiatankegiatan sekolah, salah satunya pada kegiatan penerimaan calon siswa dan siswi baru. Pemilihan media promosi yang tepat dan efektif merupakan bagian dari strategi pemasaran yang harus diterapkan agar informasi yang disampaikan akan mudah diterima oleh masyarakat luas.

Dengan latar belakang permasalahan ini, maka perlu adanya tinjauan penelitian terdahulu yang merupakan Survey literatur tentang penemuan-penemuan yang dilakukan oleh peneliti sebelumnya (Empirical fiding) yang berhubungan dengan penelitian ini sebagai bahan masukan untuk dapat mendefinisikan kelebihan dan kekurangan penelitian ini. Literature Review pada penelitian ini diantaranya: Penelitian yang dilakukan oleh Mukti Budiarto yang berjudul "Desain Media Komunikasi Visual sebagai Penunjang Kegiatan Promosi Kampus". Penelitian ini menjelaskan bahwa media promosi yang digunakan sebelumnya dalam bentuk media komunikasi visual yang berupa spanduk, stiker, umbul-umbul, buku tamu, kartu nama, baliho, banner, idcard, counselling card, packaging dan design background desktop. Dari media-media tersebut ternyata belum dapat menyampaikan informasi yang terbaru (update) karena pada tiap tahunnya akan mengalami perubahan informasi dan dari segi tampilan visualnya harus ada pergantian atau penyegaran. Hasil dari penelitian ini adalah desain media komunikasi visual yang berisi kegiatan-kegiatan prospek 2011, raharja career 2011, desain penunjang kegiatan pemasaran dari desain wallpaper dinding dengan slogan AMC dan visi, misi manajemen untuk menunjang kegiatan Misi Akreditasi [2]. 
Penelitian yang dilakukan oleh Riyanto yang berjudul "Perancangan Promosi Sekolah Sepakbola New Pelita Solo Melalui Media Desain Komunikasi Visual". Penelitian ini menjelaskan bahwa perancangan media promosi ini bertujuan untuk menarik minat masyarakat agar bergabung dengan Sekolah Sepakbola New Pelita Solo serta membangun citra Sekolah Sepakbola New Pelita Solo di masyarakat khususnya di wilayah Surakarta. Agar masyarakat lebih mengenal dan tertarik bersekolah di Sekolah Sepakbola New Pelita Solo maka diperlukan strategi promosi yang tepat untuk menyampaikan pesan maupun informasi menyeluruh tentang Sekolah Sepakbola New Pelita Solo secara jelas dan efektif [3].

Penelitian yang dilakukan oleh Saputra yang berjudul "Perancangan Media Komunikasi Visual sebagai Media Promosi Jurusan Multimedia Sekolah Menengah Kejuruan Nasional Malang”. Penelitian ini menjelaskan bahwa perancangan dari media promosi ini bertujuan untuk membangun citra/image terhadap jurusan multimedia yang dapat menginformasikan serta mengkomunikasikan jurusan multimedia di Sekolah Menengah Kejuruan Nasional Malang sehingga tidak hanya terfokus pada jurusan permesinan saja. Hasil dari perancangan ini berupa sebuah eventWorkshop dan Pameran Desain Jurusan Multimedia dengan seluruh kelengkapan media komunikasi visualnya yang meliputi directmail, poster, horizontal banner, vertikal banner, leaflet, merchandise, map, meja lobi, flagchain, x-banner, mini x-banner dan backdrop.

Penelitian yang dilakukan oleh Deka Witara yang berjudul "Perancangan Media Komunikasi Visual Penunjang Informasi dan Promosi pada PT Mida Karya Abadi Land (Savana Residence)". Penelitian ini menjelaskan bahwa media komunikasi visual yang digunakan oleh perusahaan PT. Mida Karya Abadi Land dalam program promosi propertinya hanya menggunakan media dalam bentuk visual yaitu media brosur. Oleh sebab itu, untuk melengkapi dan menunjang promosi yang dapat menarik perhatian konsumen maka dirancanglah sebuah media komunikasi visual dalam bentuk cetak. Media komunikasi visual tersebut dirancang sebagai sarana penunjang promosi yang dapat memberikan nilai lebih dalam penyampaian informasi dan penerapan strategi pemasaran. Maksud dari strategi tersebut dapat disampaikan sebagai program untuk menentukan dalam mencapai tujuan promosi [5].

Penelitian yang dilakukan oleh Mubarok yang berjudul "Desain Komunikasi Visual sebagai Sarana Promosi Sekolah Menengah Kejuruan Kesehatan Sanjiwani Gianyar". Penelitian ini menjelaskan bahwa peranan media komunikasi visual sangatlah diperlukan dalam menunjang kegiatan promosi yang dilakukan oleh SMK Kesehatan Sanjiwani Gianyar pada setiap tahunnya. Perancangan media komunikasi visual ini dibuat dengan tujuan agar dapat memperluas informasi tentang keberadaan SMK ini di kalangan masyarakat dan dapat meningkatkan jumlah calon murid baru yang akan bersekolah di SMK Kesehatan Sanjiwani Gianyar [6].

Penelitian yang dilakukan oleh Saputro yang berjudul "Media Komunikasi Visual sebagai Sarana Promosi Kurnia Creative Design (Advertising) untuk Masyarakat Surakarta". Penelitian ini menjelaskan bahwa permasalahan yang masih dihadapi oleh Kurnia Creative Design yaitu masih kurangnya informasi dan sarana media promosi kepada masyarakat luas. Dengan demikian dibutuhkan perancangan media promosi yang baru yang lebih efektif sehingga diharapkan mampu mewujudkan tujuan awal yaitu untuk mengenalkan Kurnia Creative Design secara luas kepada masyarakat Surakarta khususnya dan juga seluruh masyarakat Indonesia pada umumnya [7].

Perbedaan penelitian ini dengan penelitian terdahulu diatas, sebagai berikut :

1) Penelitian ini membuat desain komunikasi visual dalam bentuk Tabloid yang tidak dimiliki oleh penelitian-penelitian yang terdahulu. 
2) Penelitian ini memilih bentuk Tabloid sebagai sarana promosi yang efektif dan menjangkau masyarakat luas berbagai kalangan, karena Tabloid dapat menarik perhatian mereka untuk lebih mengenal SMK Mandiri 2 dan ini tidak dilakukan oleh penelitian sebelumnya.

3) Hasil Penelitian ini telah diimplementasikan langsung ke SMK Mandiri 2 dan masih digunakan sampai sekarang.

Rumusan masalah pada penelitian ini, antara lain: Media apa yang efektif dalam menunjang kegiatan promosi pada SMK Mandiri 2, sehingga masyarakat luas dapat dengan mudah mengenal sekolah ini. Masalah selanjutnya yaitu jenis desain media komunikasi visual apa yang menarik perhatian masyarakat terhadap sekolah SMK Mandiri 2 agar pesan yang disampaikan kepada mereka tepat sasaran dan lebih efektif. Pertanyaan-pertanyaan tersebut harus dicari solusinya dan digali dalam penelitian ini, maka dipilihlah media komunikasi visual berbentuk Tabloid yang kemudian penelitian ini dibatasi ruang lingkup penelitiannya yang terbatas hanya pada Desain Media Komunikasi Visual berbentuk Tabloid sebagai sarana promosi yang dikhususkan untuk SMK Mandiri 2.

\section{METODE PENELITIAN}

Penelitian ini memiliki beberapa metode penelitian, yaitu: Metode pengumpulan data, Metode analisa desain media, serta Metode konsep produksi media (KPM). Metode pengumpulan data terbagi menjadi 3 (tiga) cara, yaitu: 1) Metode Observasi yang dilakukan untuk pengambilan data yang diperlukan untuk desain media komunikasi visual berbentuk tabloid dengan melakukan pengamatan dan membuat pencatatan secara sistematik terhadap unsur-unsur yang telah diteliti dengan tujuan secara langsung pada SMK Mandiri 2. 2) Metode Wawancara (Interview) berupa pengumpulan data dengan cara bertatap muka langsung dengan orang yang akan diwawancarai, untuk memperoleh informasi yang lebih jelas dan gambaran mengenai pembuatan desain komunikasi visual berbentuk tabloid seperti apa yang diinginkan oleh SMK Mandiri 2. 3) Studi Pustaka berupa pengumpulan data-data berupa teori, yang terdapat didalam buku-buku, jurnal dan literature review yang berkaitan dengan judul penelitian ini. Metode analisa desain media menggunakan media komunikasi visual berbentuk tabloid, dimana desain media ini sangat dibutuhkan oleh SMK Mandiri 2, dibuat dan diproduksi dengan menggunakan aplikasi program komputer grafis. Media yang akan digunakan sebagai sarana penunjang sosialisasi tersebut dirancang dengan menggunakan aplikasi Adobe Premiere Pro CC, Adobe Photoshop CC dan Adobe Illustrator CC. Metode Konsep Produksi Media (KPM) memiliki tahapan-tahapan proses konsep produksi media yaitu: 1) Preproduction (Pra Produksi), 2) Production (Produksi) dan 3) Postproduction (Pasca Produksi).

\section{HASIL DAN PEMBAHASAN}

\subsection{Perancangan Media}

Media informasi dan promosi yang digunakan sebagai penunjang kegiatan promosi SMK MANDIRI 2 merupakan media-media yang dirancang dalam bentuk media komunikasi visual yang disesuaikan dengan kebutuhan sosialisasi atau penyelenggaraan kegiatan promosi. Media yang dimaksud yakni dalam bentuk Tabloid, karena media ini dinilai efektif, dapat diterima semua kalangan dan dapat menjangkau masyarakat luas. Tabloid merupakan surat kabar ukuran kecil (setengah dari ukuran surat kabar biasa) yang banyak memuat berita secara singkat, padat dan bergambar, mudah dibaca umum, selain itu tabloid merupakan tulisan dalam bentuk ringkas dan padat (tentang kritik, paparan dan sebagainya). Tabloid merupakan media yang paling simple organisasinya, mudah mengelolanya, serta tidak membutuhkan modal yang banyak, maka tabloid dapat diterbitkan oleh setiap kelompok masyarakat, tetapi dalam hal ini tabloid merupakan salahsatu bentuk media massa khususnya media cetak, dimana fungsi media massa yakni menyiarkan informasi, mendidik, menghibur dan mempengaruhi [8].

3.2 Konsep Kreatif 
Konsep kreatif yang akan ditampilkan kedalam media penunjang kegiatan promosi pada SMK Mandiri 2 dengan menampilkan informasi yang update terkait informasi penerimaan calon siswa dan siswi baru serta menambahkan elemen grafis pendukung lainnya yang disesuaikan dengan tema yang telah ditentukan dalam setiap media. Dalam desain Tabloid ini akan disertai dengan logo SMK Mandiri 2, gambar-gambar, serta terdapat teks yang menarik dan sudah disesuaikan penempatannya untuk menginformasikan isi dari setiap desain, selain itu warna yang ditampilkan secara mayoritas yaitu warna biru sebagai warna identitas SMK Mandiri 2 serta penambahan warna putih dan merah untuk menampilkan terkesan terang, menarik dan sesuai dengan sekolah SMK Mandiri 2.

3.3 Penulisan Naskah

Pada desain media komunikasi visual berbentuk tabloid untuk SMK Mandiri 2 terdapat unsur-unsur komunikasi grafis seperti teks (tulisan), ilustrasi (foto atau image), warna dan elemen desain. Salah satunya merupakan naskah atau teks (tulisan) sebagai headline ataupun subheadline bodycopy yang diperlukan dalam perancangan agar penyampaian informasi dapat mudah dimengerti dan tepat sasaran, teks digunakan sebagai judul (headline), subjudul, naskah (body copy) dan logo (logo type). Naskah merupakan sebuah cerita yang menguraikan urutanurutan adegan, tempat, keadaan dan dialog, yang disusun dalam konteks struktur dramatic untuk menjadi acuan dalam proses produksi [9]. Penulisan naskah ini diperlukan untuk menginformasikan seluruh kegiatan-kegiatan yang diselenggarakan oleh pihak sekolah SMK Mandiri 2.

3.4 Pengarahan Visual

Warna yang dipilih adalah biru, putih, dan merah. Dengan dominan warna biru yang mencirikan identitas SMK Mandiri 2. Jenis huruf yang dipakai dalam perancangan media ini diantaranya menggunakan beberapa jenis huruf yang karakternya lebih sesuai dengan karakter huruf yang selama ini dipergunakan, yaitu: Bauhaus 93, Arial, Arial Black, Franklin Gothic Heavy dan Britannic Bold. Gaya tampilan visual secara grafis ditampilkan dengan kombinasi warna bernuansa biru, putih dan merah sehingga terlihat terang dan menarik perhatian masyarakat.

3.5 Proses Desain

3.5.1 Layout Kasar

Layout kasar merupakan penerapan elemen-elemen desain media yang nantinya akan dipergunakan dalam perancangan media komunikasi visual yang disertai acuan standarisasi pada desain yang akan dibuat, umumnya dibuat dengan tampilan hitam putih, dibuat dengan coretan atau sketsa dengan menggunakan pensil gambar. Layout kasar diperlukan sebagai panduan pada saat proses desain dengan menggunakan aplikasi komputer.

3.5.2 Layout Komprehensif

Layout komprehensif merupakan proses desain yang sudah memasuki tahap komputerisasi dan pewarnaan, namun tahap ini belum selesai seutuhnya, karena masih harus mengalami proses revisi.

Dibawah ini merupakan bentuk Layout Kasar dan Layout Komprehensifnya : 


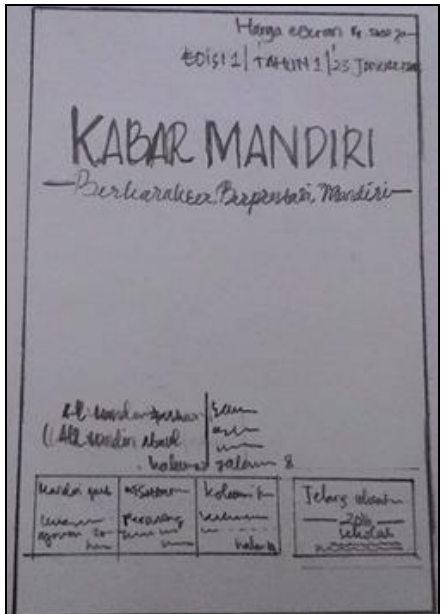

Gambar 1. Layout Kasar Cover Tabloid

Keterangan gambar 1 : Gambar 1 diatas menggambarkan hasil layout kasar Cover Tabloid yang telah finish berupa media dengan ukuran $24 \mathrm{~cm} \times 33 \mathrm{~cm}$. bahan pada media ini menggunakan Art Carton 260 gsm, pada bagian cover ini didesain full colour dengan tujuan agar menarik perhatian dan enak dipandang sehingga mengundang minat para pembaca.

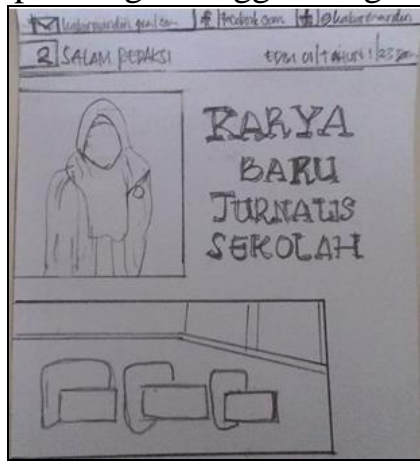

Gambar 2. Layout Kasar Salam Redaksi

Keterangan gambar 2 : Gambar 2 diatas menggambarkan hasil layout kasar Salam Redaksi yang telah finish berupa media dengan ukuran $24 \mathrm{~cm} \times 33 \mathrm{~cm}$. bahan pada media ini menggunakan Art Carton 260 gsm, Salam Redaksi merupakan halaman awal sebagai salam pembuka pada tabloid.

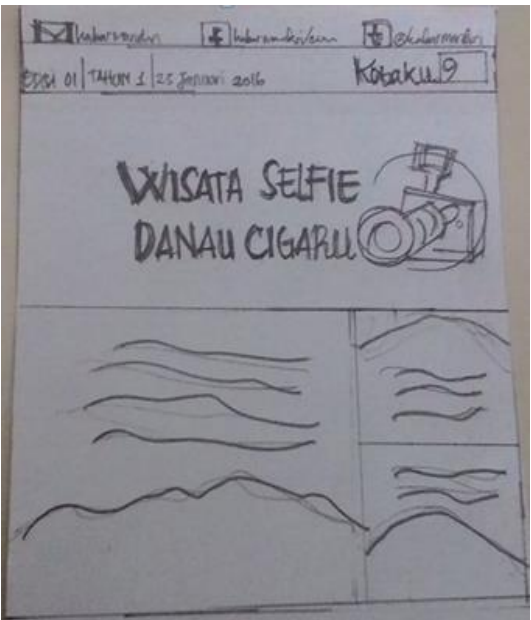

Gambar 3. Layout Kasar Kotaku 
Keterangan gambar 3 : Gambar 3 diatas menggambarkan hasil layout kasar Kotaku yang telah finish berupa media dengan ukuran $24 \mathrm{~cm}$ x $33 \mathrm{~cm}$. bahan pada media ini menggunakan Art Carton 260 gsm, menerangkan sebuah tempat wisata di kota Tangerang-Banten yang bernama Danau Cigaru yang saat ini menjadi destinasi wisata baru bagi warna Tangerang dan merupakan tempat para muda-mudi berfoto selfie mengabadikan tempat yang indah ini.

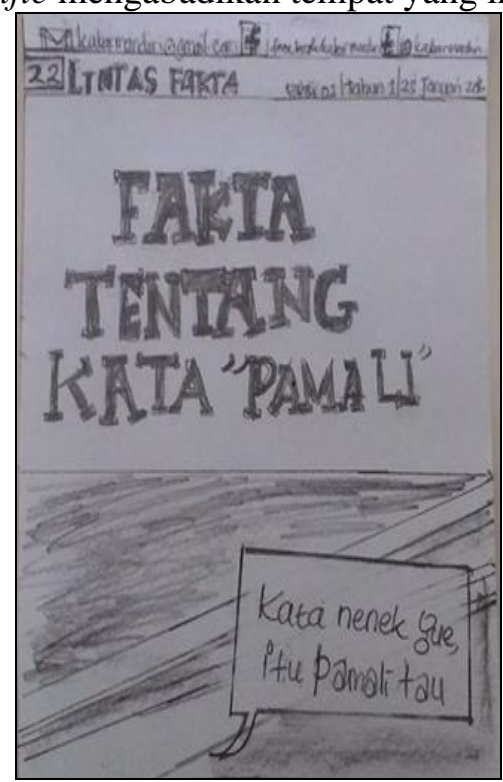

Gambar 4. Layout Kasar Lintas Fakta

Keterangan gambar 4 : Gambar 4 diatas menggambarkan hasil layout kasar Lintas Berita yang telah finish berupa media dengan ukuran $24 \mathrm{~cm} \times 33 \mathrm{~cm}$. bahan pada media ini menggunakan Art Carton 260 gsm, Fakta tentang kata Pamali, yakni: kata Pamali sering sekali terdengar diucapkan oleh orang Sunda yang maknanya adalah Pantangan. Kata Pamali merupakan hal-hal yang sering kita dengar dari orangtua kita/kakek nenek pada zaman dahulu, Pamali itu tanggapan yang menurut budaya/adat adalah sesuatu yang tidak boleh dilakukan karena bisa mendatangkan hal-hal yang buruk.

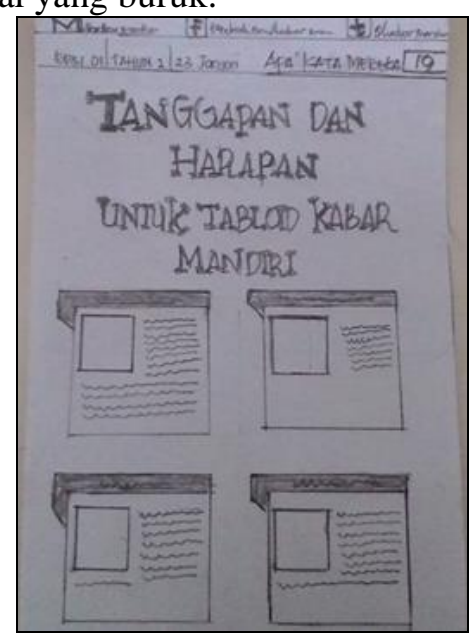

Gambar 5. Layout Kasar Apa Kata Mereka 
Keterangan gambar 5: Gambar 5 diatas menggambarkan hasil layout kasar Apa Kata Mereka yang telah finish berupa media dengan ukuran $24 \mathrm{~cm} \times 33 \mathrm{~cm}$. bahan pada media ini menggunakan Art Carton 260 gsm, pada gambar tersebut menjelaskan tentang Tanggapan dan harapan untuk tabloid kabar Mandiri yang merupakan pendapat pada tenaga pengajar/guru-guru mengenai sekolah SMK Mandiri 2, yang merupakan bahan masukan untuk kemajuan sekolah SMK Mandiri 2.

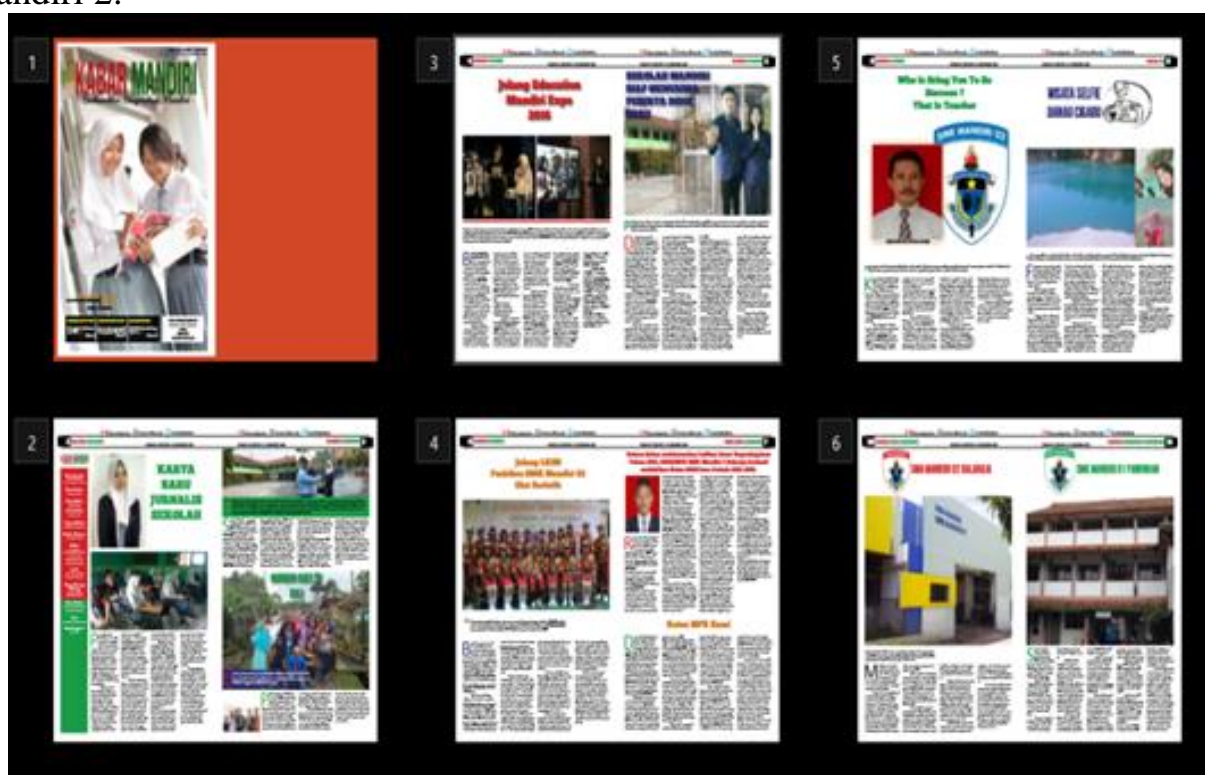

Gambar 6. Layout Komprehensif Media Komunikasi Visual

Keterangan gambar 6 : Gambar 6 diatas menggambarkan Layout Komprehensif Media Komunikasi Visual yang menjelaskan tentang proses desain yang sudah memasuki tahap komputerisasi dan pewarnaan, namun pada tahap ini belum selesai seutuhnya, karena masih harus mengalami proses revisi. Jika telah di revisi, maka Layout Kompherensif Media Komunikasi Visual ini berupa Final Artwork.

\subsubsection{Final Artwork}

Final Artwork merupakan hasil akhir dari layout komprehensif yang telah diperbaiki, dimana pada tahap ini merupakan hasil akhir atau finishing, yang kemudian dapat digunakan untuk acuan saat proses produksi. Final artwork merupakan istilah untuk file desain akhir yang siap cetak/print. Ada beberapa poin penting yang harus diperhatikan dalam menyiapkan final artwork untuk menghindari kesalahan pada saat cetak yang kemungkinan berujung pada hasil produksi yang tidak memuaskan. Poin penting final artwork antara lain: Bleed, Convert Font, Resolusi, Mode Warna, Crop Mark, ukuran Artwork dan Image link [10].

Berikut tahapan proses akhir setelah layout komprehensif yang berupa Final Artwork dalam desain media komunikasi visual berbentuk tabloid pada SMK MANDIRI 2 : 


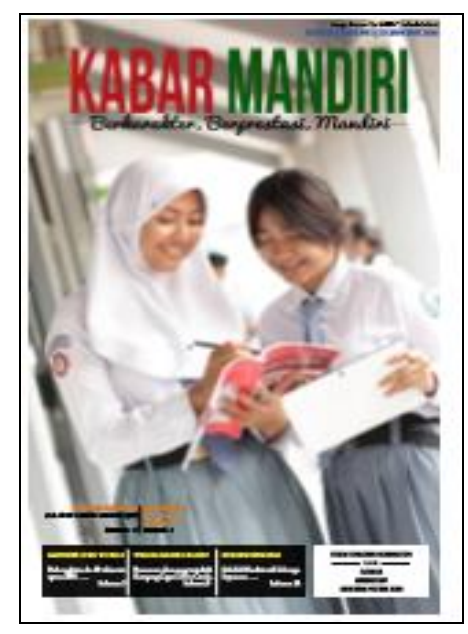

\section{Gambar 7. Final Artwork Cover Mandiri}

Keterangan gambar 7 : gambar 7 diatas menerangkan hasil akhir yang telah finish pada media tabloid ini dibuat menggunbakan software adobe indesign yang didalamnya menampilkan logo SMK Mandiri 2 dengan status akreditasi, program keahlian, nomor telp. sekolah, tanggal dimulainya pendaftaran calon siswa-siswi baru serta terdapat image/foto dua orang siswi, sebagai media pendukung perancangan desain dan seluruh informasi yang ditampilkan pada media tabloid ini ditujukan kepada calon siswa/siswi baru dan masyarakat.

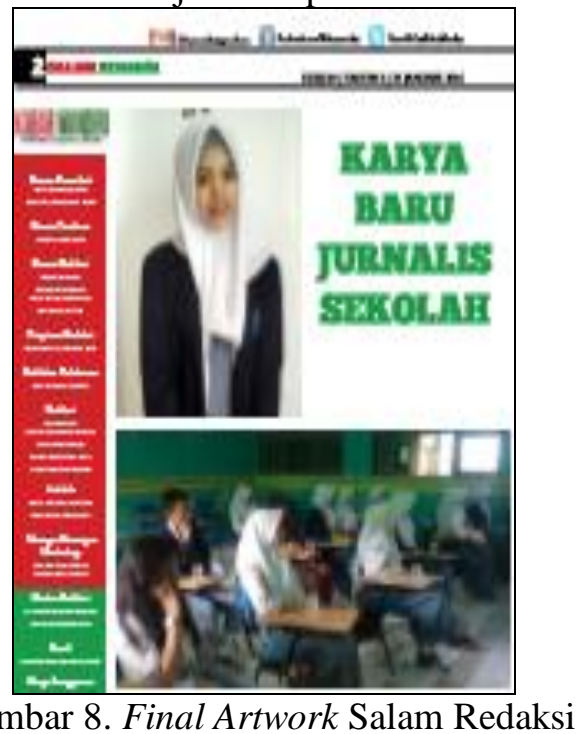

Keterangan gambar 8 : gambar 8 diatas menerangkan hasil akhir yang telah finish yang siap cetak, dan dalam pembuatannya menggunakan software adobe indesign yang menampilkan siswa-siswi SMK Mandiri 2 dalam proses kegiatan belajar mengajar diruang kelas. Selain itu juga terdapat pelatihan penulisan karya jurnalis sekolah yang bertujuan untuk melatih para siswa-siswi SMK Mandiri 2 untuk memiliki keahlian menulis. 


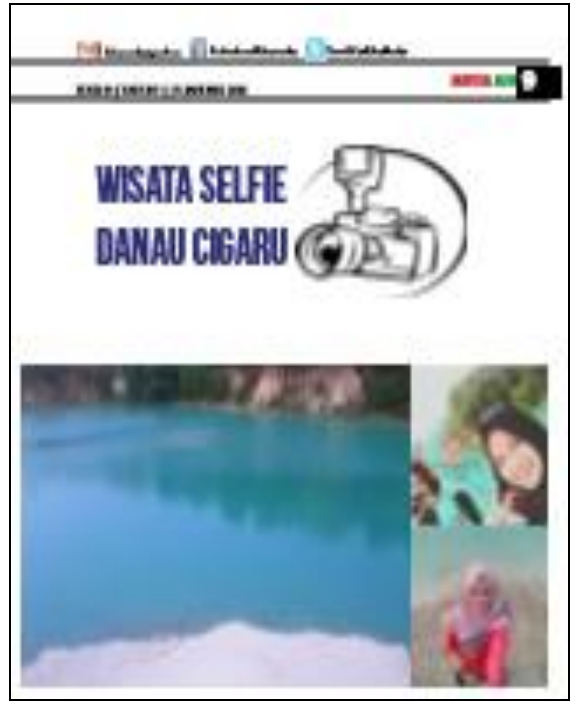

Gambar 9. Final Artwork Kotaku

Keterangan gambar 9 : gambar 9 diatas menerangkan hasil akhir yang telah finish yang siap cetak dan dalam pembuatannya menggunakan software adobe indesign dengan menampilkan Danau Cigaru. Danau Cigaru terbentuk dari sisa-sisa galian pasir pada waktu silam dan karena terdapat sumber air yang cukup besar yang menggenangi seluruh permukaan galian, maka aktifitas penambangan pada saat itu diberhentikan selama kurang lebih 10 tahun. Panorama keindahan Danau Cigaru ini kemudian mulai dikenal luas oleh masyarakat Tangerang. Lokasi Danau Cigaru ini sering dijadikan tempat wisata dan berfoto oleh para wisatawan.

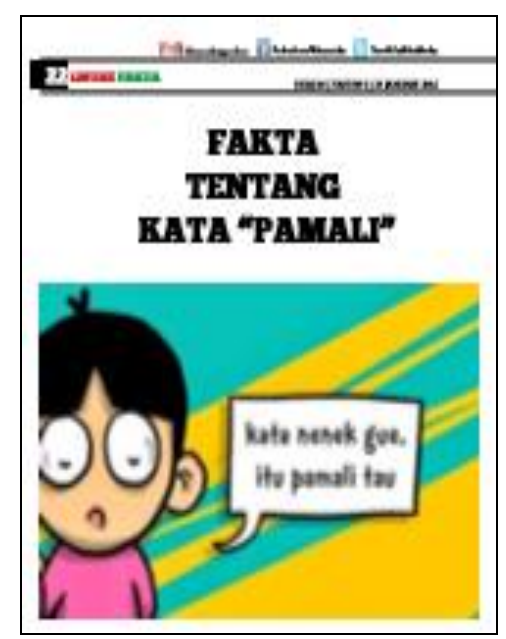

Gambar 10. Final Artwork Lintas Fakta

Keterangan gambar 10 : gambar 10 diatas menerangkan hasil akhir yang telah finish yang siap cetak dan dalam pembuatannya menggunakan software adobe indesign dengan menampilkan ilustrasi fakta tentang kata Pamali. 


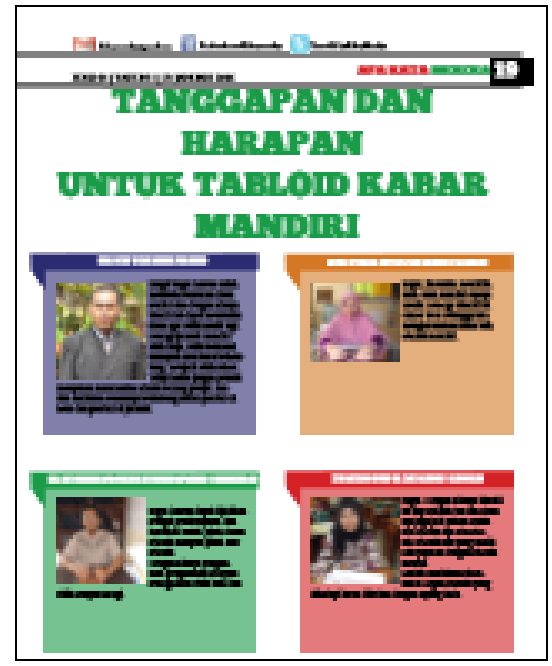

Gambar 11. Final Artwork Apa kata Mereka

Keterangan gambar 11 : gambar 11 diatas menerangkan hasil akhir yang telah finish yang siap cetak dan dalam pembuatannya menggunakan software adobe indesign yang menampilkan foto, tanggapan dan harapan para tenaga pengajar/guru terhadap sekolah SMK Mandiri 2.

\section{Pengujian Blackbox Testing}

Untuk mendapatkan hasil uji, maka dilakukan tahap pengujian menggunakan metode Blackbox Testing, untuk memastikan bahwa desain media komunikasi visual berbentuk Tabloid yang dibuat ini masih terdapat bug (kesalahan) atau tidak.

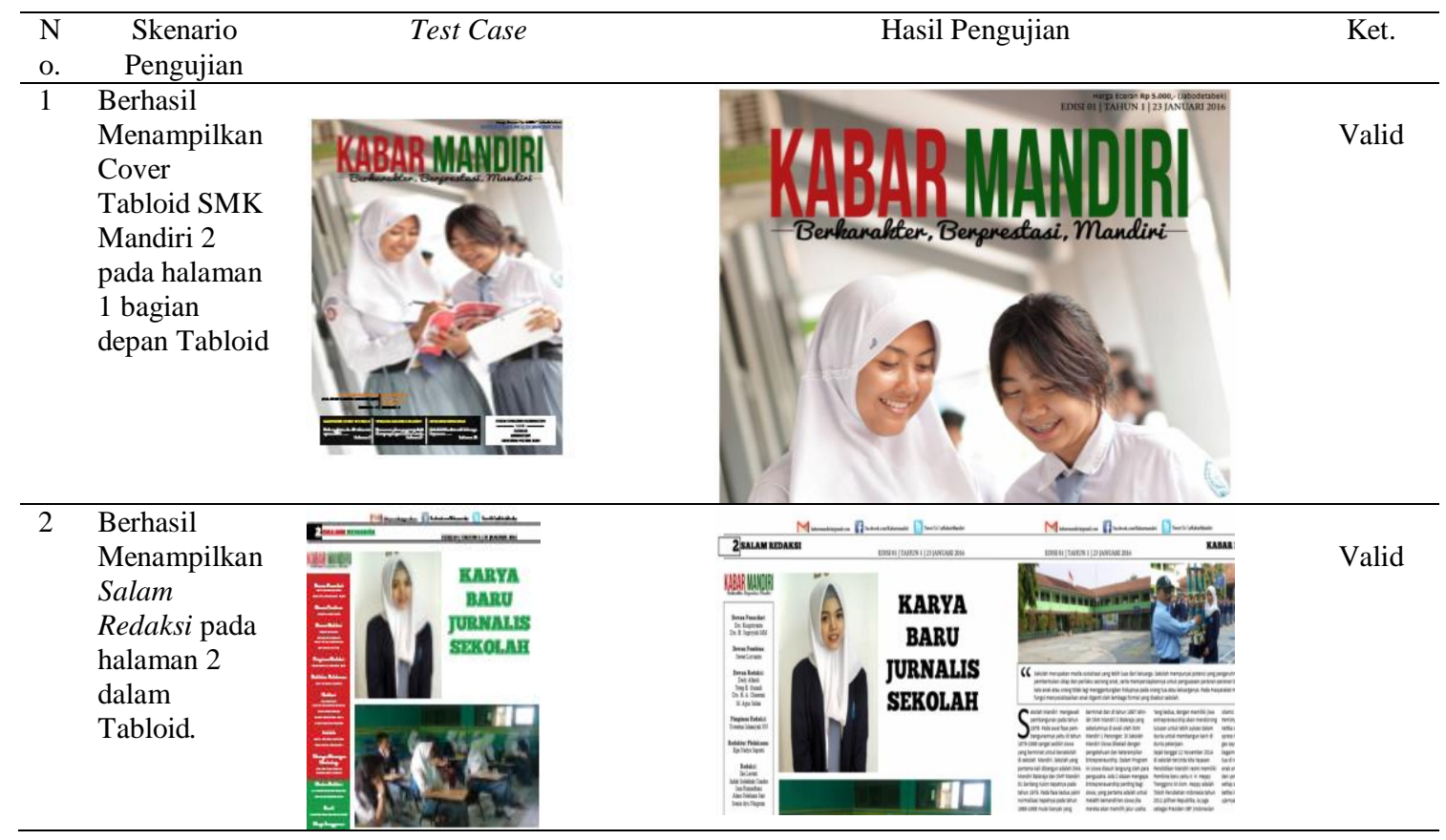


Desain Media Komunikasi Visual Berbentuk Tabloid ...

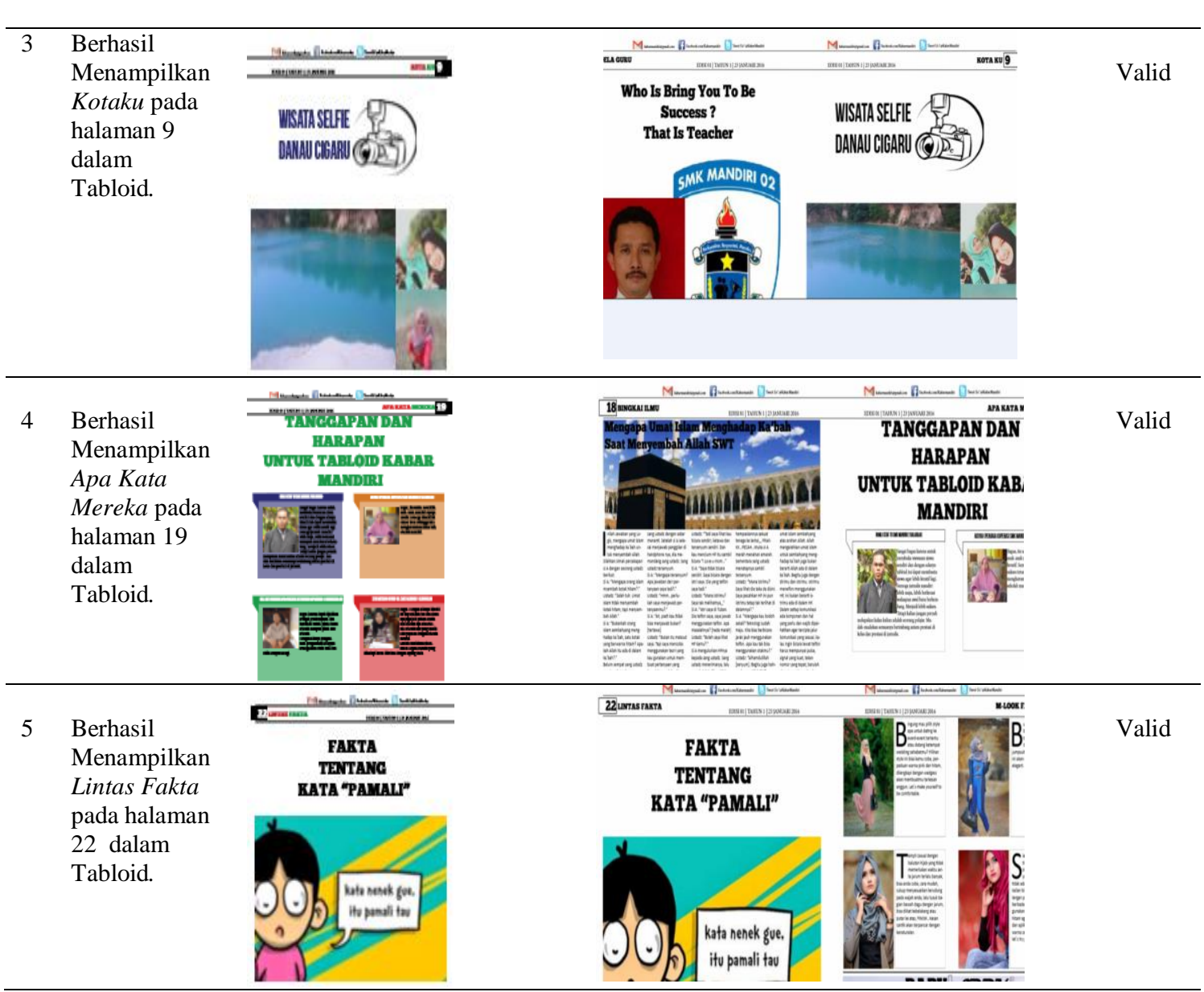

4. KESIMPULAN

Kesimpulan pada penelitian ini antara lain :

1) Media yang efektif dalam menunjang kegiatan promosi pada SMK MANDIRI 2 adalah media komunikasi visual dalam bentuk cetakan, yang dapat menarik perhatian dan dapat diterima oleh berbagai kalangan masyarakat.

2) Jenis desain media komunikasi visual yang menarik perhatian masyarakat terhadap sekolah SMK MANDIRI 2 ternyata berupa media yang berbentuk Tabloid.

\section{SARAN}

Saran dari penelitian ini : 1) Disarankan agar media komunikasi visual dalam bentuk cetakan (dalam hal ini Tabloid) yang telah dibuat, dapat dikembangkan lebih lanjut sebagai sarana promosi yang menarik dan dapat memenuhi tujuan yang ingin dicapai oleh SMK MANDIRI 2 yakni meningkatkan jumlah penerimaan siswa-siswi baru. $\quad 2$ 2) Disarankan agar tabloid yang telah dibuat disempurnakan lebih lanjut dan memiliki team khusus yang menangani dan mengurusi media promosi tabloid ini agar informasinya selalu up to date, semakin digemari masyarakat dan akhirnya banyak orangtua yang akan mendaftarkan anakanaknya di SMK MANDIRI 2.

\section{UCAPAN TERIMAKASIH}

Penulis mengucapkan Terimakasih kepada: Bpk.Ir. Untung Rahardja,M.T.I., selaku Ketua STMIK Raharja dan Bpk.Dr. PO.Abas Sunarya,M.Si, selaku Direktur AMIK Raharja yang telah 
memberi dukungan financial terhadap penelitian ini dan kepada Kepala Sekolah SMK MANDIRI 2 yang telah memberikan dukungan penuh kepada penulis sehingga tercipta penelitian ini.

\section{DAFTAR PUSTAKA}

[1] Lusyani,S.,Radiyanto.,Erna,S.(2013). Enriching Company Profile sebagai penunjang media informasi dan promosi pada Perguruan Tinggi Raharja. Tangerang: CCIT Journal.(Vols.7).

[2] Budiarto,M., Yohanes,A.K.Y., Maimunah, Lusyani,S.(2012). Desain Media Komunikasi Visual sebagai Penunjang Kegiatan Promosi Kampus. Bali: Eksplora Informatika Journal,(Vols.1).

[3] Riyanto.,\&Nurcholis,S.(2011). Perancangan Promosi Sekolah Sepakbola New Pelita Solo Melalui Media Desain Komunikasi Visual. Surakarta: Universitas Sebelas Maret.

[4] Saputra.,\&Arieza,H.(2011). Perancangan Media Komunikasi Visual sebagai Media Promosi Jurusan Multimedia Sekolah Menengah Kejuruan Nasional Malang. Jawa Timur: Universitas Negeri Malang.

[5] Witara,D.(2016). Perancangan Media Komunikasi Visual Penunjang Informasi dan Promosi pada PT Mida Karya Abadi Land (Savana Residence). Tangerang: STMIK Raharja.

[6] Mubarok.,\&Andri.(2012). Desain Komunikasi Visual sebagai Sarana Promosi Sekolah Menengah Kejuruan Kesehatan Sanjiwani Gianyar. Denpasar Bali: Institut Seni Indonesia.

[7] Saputro,E.K.(2011). Media Komunikasi Visual sebagai Sarana Promosi Kurnia Creative Design (Advertising) untuk Masyarakat Surakarta. Surakarta: Universitas Sebelas Maret.

[8] Khodijah,S.(2016) Etika pemberitaan media massa dan tabloid. Retrieved November 22, 2016 from http://library.walisongo.ac.id/digilib/files/disk1/16/jtptiain-gdl-sl-2006sitikhotij-772-BAB2_110-8.pdf

[9] Arddiyana.(2015). Pengertian naskah, fungsi naskah, storyboard dan langkah-langkah membuat storyboard. Retrieved January 10, 2017 from http://www.brainly.co.id

[10] Ajir.(2009). 7 poin penting dalam menyiapkan Final Artwork (FA). Retrieved January 10, 2017 from http://www.desainstudio.com 